\title{
Precision farming and archaeology
}

\author{
Henry Webber $^{1}\left(\mathbb{D} \cdot\right.$ Volker Heyd $^{1} \cdot$ Mark Horton $^{1} \cdot$ Martin Bell $^{2} \cdot$ Wendy Matthews $^{2}$. \\ Amanda Chadburn ${ }^{3}$
}

Received: 21 April 2017 / Accepted: 3 November 2017 /Published online: 22 November 2017

(C) The Author(s) 2017. This article is an open access publication

\begin{abstract}
With a significant growth in the agricultural technology industry, a vast amount of agricultural data is now being collected on farms throughout the world. Farmers aim to utilise these technologies to regularly record and manage the variation of crops and soils within their fields, to reduce inputs, increase yields and enhance environmental sustainability. In this paper, we aim to highlight the variety of different data types and methodological processes involved in modern precision farming systems and explore how potentially interconnected these systems are with the archaeological community. At present, no research has studied the effects of archaeological sites on soils in the context of precision farming practices. Yet from modern geophysical, geochemical and remote sensing techniques, a much greater volume of soil- and croprelated mapping is being undertaken, with huge potential for all kinds of archaeological study. From heritage management to archaeological prospection, how will the future of archaeological studies fit into this changing agricultural landscape?
\end{abstract}

Keywords Precision farming · Geophysics · Geochemistry · Remote sensing $\cdot$ Archaeology $\cdot$ Soils

Henry Webber

Henry.Webber@bristol.ac.uk

1 Department of Archaeology and Anthropology, University of Bristol, 43 Woodland Road, Bristol BS8 1UU, UK

2 Department of Archaeology, University of Reading, Whiteknights, PO Box 218, Reading RG6 6AA, UK

3 Historic England, 29 Queen Square, Bristol BS1 4ND, UK

\section{Introduction}

During the last decade, significant growth in the agricultural technology industry has enabled vast amounts of agricultural data to be collected on farms across the globe. These datasets are increasingly of a high resolution and cover much larger spatial and temporal ranges than previous agricultural datasets. From mapping within-field soil variability to GPSbased auto-steering, this revolution of twentieth century agriculture is changing how farms are run and will continue to in the future. The question is, how does archaeology fit into this new agricultural landscape? Many archaeological remains, known and unknown, lie within agricultural soils and under the management of 'standard' farm operations. Many geophysical surveys are completed each year to identify and characterise archaeological sites. But what will the future bring for archaeological prospection and heritage management within these changing agricultural landscapes?

\section{Precision farming}

'Precision farming' practices, also known as 'precision agriculture' or 'site-specific farming', have been used within agriculture for several decades, but within the past few years have become more common. Precision farming aims to utilise technology to record and manage the variation of crops and soils within a field, thus reducing surplus inputs (e.g. fertiliser), increasing yields and aiding environmental sustainability (Oliver et al. 2013; Stafford 2000). Precision farming includes many technologies such as satellite imagery, geophysics, yield mapping and global positioning systems enabling variable rate fertiliser application and variable depth cultivation, all integrated within farm management software (JRC and MARS 2014). Precision farming represents a new 
level of high-resolution data collection on farms with regard to soil mapping, soil nutrient analysis and crop growth data. All of these can lead to better analytics using data from real farms for informing management decisions instead of small, replicated trial plots that do not compare to real world applications. In this sense, precision farming may transform agronomic science into advice that is targeted to each farm's individual social, economic and environmental context.

There are several motivations for farmers to take up precision farming methods and the associated initial costs (Zhang et al. 2002). These can vary, depending on the nature of the local environment, the policy landscape and economic environment (McBratney et al. 2005). In the UK, farmers base their engagement with precision farming technology on the practicality of adapting it to existing farm machinery and farmers' perceptions of what methods 'work' and which do not (Parliamentary Office for Science and Technology 2015).Currently, around $60 \%$ of the UK's farmland is under some form of 'precision farming' management (http://www. nesta.org.uk/blog/precision-agriculture-separating-wheatchaff accessed on 7 November 2016) (Fig. 1).

\section{Soils: connecting archaeology to precision farming}

One of the key underpinning knowledge bases of precision farming is the variability of soils. Due to the, often, large areas covered by farmers, this usually is assessed by mapped data, without actual field inspection. To understand the variation in a crop remotely, and more importantly what is causing it, one must understand the variation in the soils at the appropriate scale. Only then can alternative causes be established by further inspection (e.g. pest/disease scouting) and corrected if necessary. This resolution was previously at the whole-field level, but is now necessary at the $5-20 \mathrm{~m}$ level to manage small areas effectively, and is possible due to more accurate machinery. Archaeologists depend on soils just as much. Archaeological remains buried within the soil profile depend on that soil for their conservation. Soils also provide a unique context for learning about the archaeological remains themselves both spatially and vertically, providing vital and sometimes detailed records of soil history and depositional processes. To interpret anomalies correctly, archaeological geophysicists regularly require more detailed and higher-resolution information of soils than is available from existing soil maps. Geochemical studies of archaeological sites equally need a robust grounding in the geochemical variation of soils at the appropriate resolutions to enable accurate interpretations.

Soils, and how those soils vary over space and time, are clear connections between archaeology and precision farming. The resolutions of agricultural and archaeological datasets are far more interconnected and complimentary now, than in the past. Traditionally in the UK, common agricultural perspectives consider archaeological sites as generally small in extent and agriculturally insignificant. These perspectives can be misleading and do not consider the wide variation of different types of known archaeological sites that may be of agricultural significance. Simultaneously, the increasing level of detail in agricultural management also magnifies the potential for archaeological sites to have more agricultural impact. However, from an archaeological perspective, there may be many archaeologists who are unaware of the types and resolutions of data that now exist in the agricultural world and how they may relate to archaeological prospection and heritage management. Here are clear overlaps of not only data, but also the interest in and the desire to understand soils better.

\section{Examples}

The following are a few examples taken from case study sites in the UK to illustrate the ideas discussed above. They are not meant to present conclusive research that has been fully evaluated, but are intended to promote thinking in this new area of research and suggest areas of future debate.

\section{Soil management zones}

A common approach to precision farming in many countries is the zone management approach (Whelan and McBratney 2003). This approach aims to identify soil variations, map them and characterise them, to inform better management. An example of this approach is illustrated in Fig. 2. Here, freely available satellite imagery, geological mapping from the British Geological Survey and a soil reflectance image from the Intelligent Precision Farming company were combined with other types of data (e.g. a farmer's own interpretation) to produce soil management zones. The precision farming company then samples those zones for soil nutrients (available phosphate, potash, magnesium and $\mathrm{pH}$ ) and automatically creates variable rate fertiliser plans for each zone.

The geophysical survey (Fig. 2), for the same site, shows potentially how an archaeological site might interact in this situation. The magnetic gradiometer survey shows two linear anomalies enclosing the centre ground, with an interpreted small Iron Age enclosure in the smaller field with several pit-like anomalies. This enclosure does not show clearly in any of the existing soil data, yet does influence crop growth in a Normalised Difference Vegetation Index (NDVI) satellite image from the 27 February 2015 (see Fig. 3). This demonstrates that the typical precision farming approach to soil mapping (although suited to a certain scale) can miss soil variation that transcends these scales, and that could have been acknowledged if existing archaeological information was included initially in the soil zoning process. This omission could 


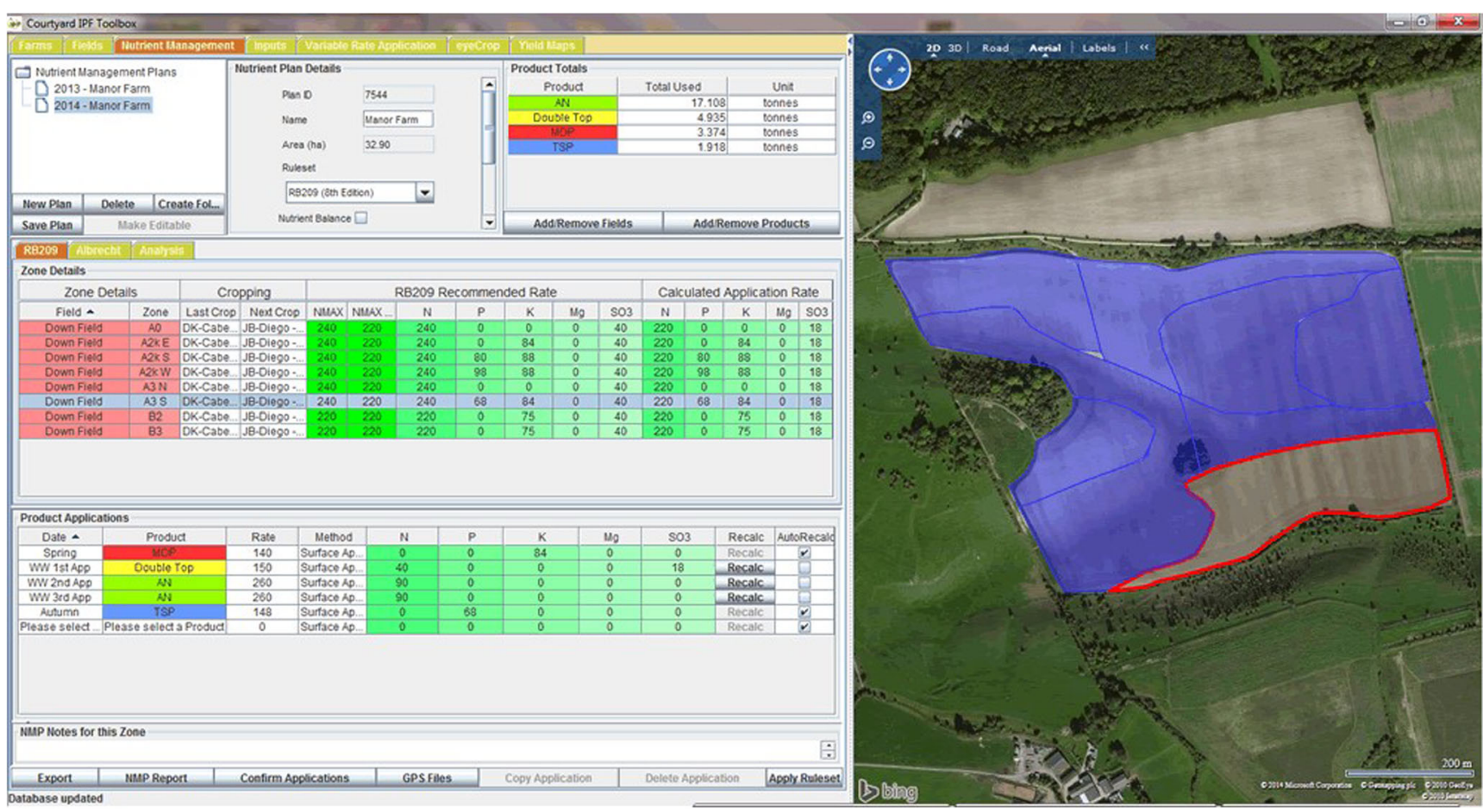

Fig. 1 An image of the 'Toolbox' interface for farmers and agronomists (courtesy of the Intelligent Precision Farming company)

also mislead further interpretations as to why this area of crop was different, or how it could be managed in the future.

\section{Remote sensing}

Remotely sensed satellite imagery can be used for a wide variety of applications within precision farming (Seelan et al. 2003; Mulla 2013). The soil brightness image in Fig. 2 represents light reflectance from the soil surface in four different wavebands (including infrared) to identify changes in soil texture, organic matter, moisture, calcium carbonate and stone content at a 5-m resolution (http://www.ipf-uk.com/precisionfarming/soil-zoning/soil-brightness.html accessed 27 February 2016). Other spectral characteristics are also used to determine how healthy a crop is at certain times of the year. The most common vegetative index used within precision farming is the NDVI index. This produces results relating to a crop's 'greenness' and its leaf area index. Due to the increasing temporal availability and spatial resolution of satellite imagery, this technique has seen much use in the UK, and internationally, to monitor crop health, weeds and even drainage throughout the growing season (Lamb and Brown 2001; https://sa.catapult.org.uk/documents/10625/53165/ The+Courtyard+Partnership+case+study/26073572-f15f41ae-8480-9857b682e84e accessed 27 February 2016).

Figure 3 shows three satellite images typical of precision farming application in the UK. These images are used to plan nitrogen fertiliser applications variably across the field, for example to feed poor areas of crop, or reduce application on nutrient-rich areas. They help to provide farmers with a quick method of assessing their crops, at the same time as providing a detailed record of crop growth throughout the year.

Comparing the image from the 27 February 2015 to the geophysical survey shown in Fig. 2, there are clear correlations between the small Iron Age enclosure and the growth of oilseed rape at that time. This is interesting for two reasons; firstly, oilseed rape is not a crop well known for producing archaeological crop marks due to its low plant density and branching canopy. Secondly, during the winter, it is not common to gather aerial imagery because of poor weather conditions but also due to the expected lack of archaeological feature detection (i.e. moisture deficit). Yet perhaps there is progress to be made from talking to farmers about satellite data, helping them to understand the variations seen from an agricultural, pedological and an archaeological stance without which, anomalies in satellite and other data may be wrongly associated. It may also be helpful for archaeologists to understand the possibilities that a range of crops may produce archaeological crop marks under certain conditions and at times of the phenological cycle not realised before. In addition to this is the obvious advantage that there is simply more temporal and spatial data out there which, if it can be accessed, could be used to enhance the archaeological record if interpreted correctly.

\section{Soil geophysics}

The use of geophysical surveys within precision farming has mainly focused on electrical conductivity surveys (Allred 


\section{Case study site in Dorset, UK} NGR ST969142
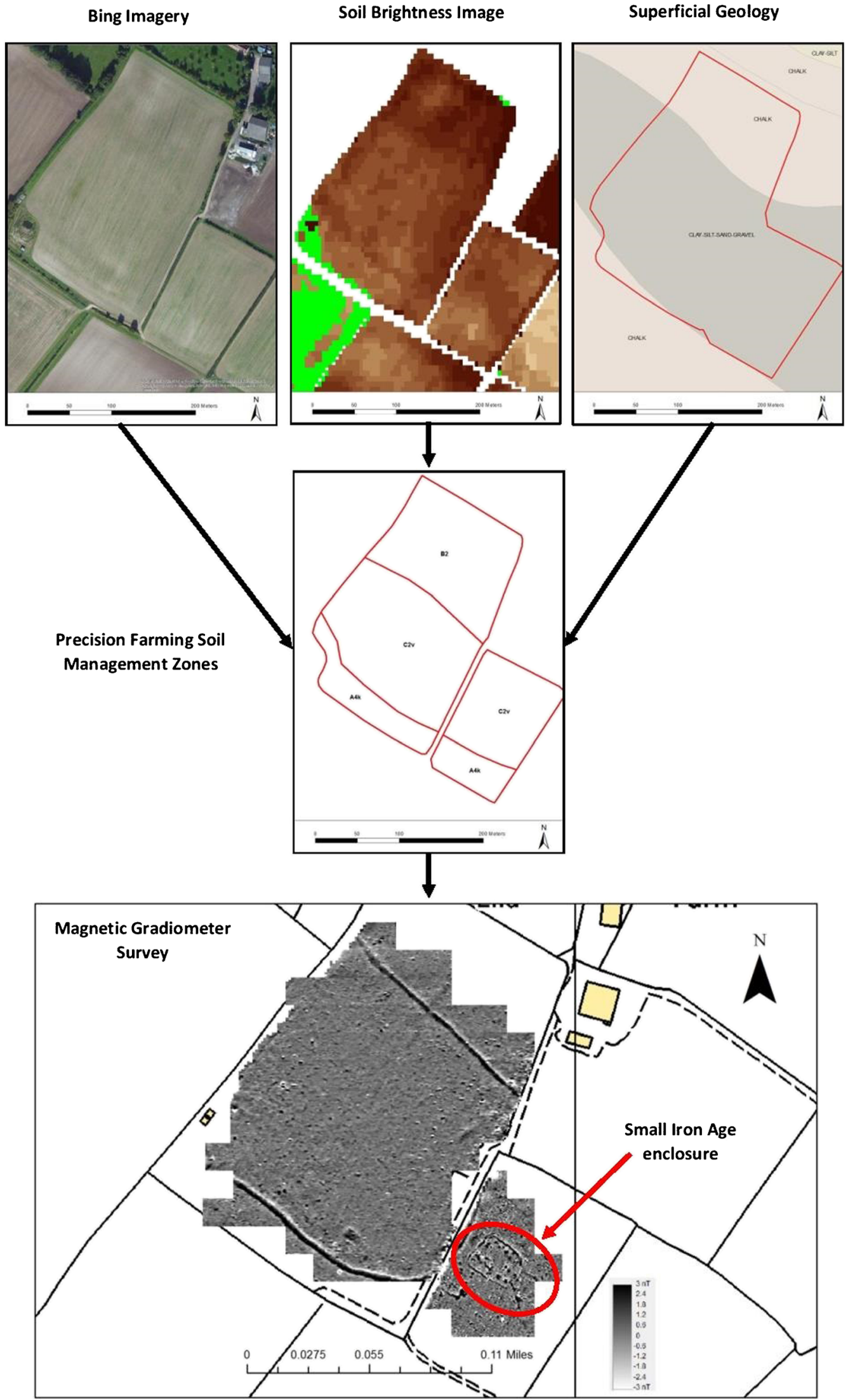
Fig. 2 Data used in a precision farming soil management zoning process and a magnetic gradiometer survey of the same site with Iron Age enclosure (images courtesy of Paul Cheetham and Amy Green (Green 2014), Intelligent Precision Farming, Bing Imagery and the British Geological Society)

et al. 2008). As the conductivity of the soil is affected by several important soil parameters such as moisture, salinity, texture, stone content and soil depth, it has proven useful to farmers as a broad indicator of agricultural soil quality. The typical types of geophysical surveys carried out by precision farming companies to determine soil management zones are often at an interval of between 10 and $24 \mathrm{~m}$ (see Fig. 4).

At the same time, archaeological geophysicists have developed a wide range of experiences using multiple near-surface geophysical methods to learn about the nature of archaeological sites. No one method has become the sole tool for an archaeological geophysicist since flexibility is essential when surveying a wide range of site types. Magnetic gradiometry is one of the most commonly used methods in the archaeological geophysics sector in most academic departments, commercial units and other organisations, but has not yet been subject to research in an agricultural context despite being noted as a method of potential (Allred et al. 2008).

An illustration of a conductivity survey is shown in Fig. 4 and is similar to what would be produced by a precision farming company. In this interesting image, there are clearly some anomalies, yet without any more detailed survey, it could not be interpreted whether these anomalies were of archaeological origin or not. Crucially, however, as a broad survey of the soil variability, this image has value for future archaeological work on the site, enabling an initial focus on areas of soil that are most variable and hold higher potential for archaeological activity.

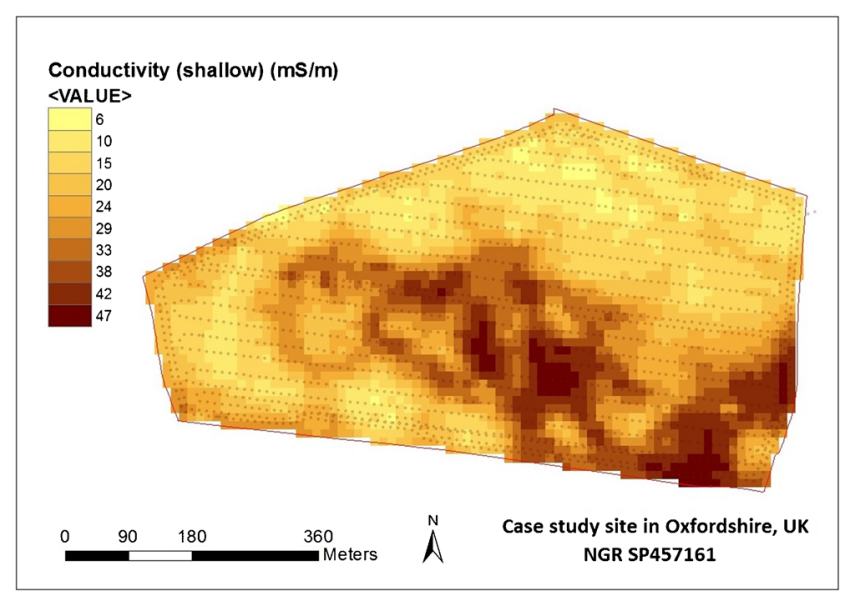

Fig. 4 Results of a precision farming conductivity survey, with the data points used to interpolate the image. Courtesy of James Price

\section{Soil geochemistry}

During the early twentieth century, the Swedish agronomist Olaf Arrhenius gained extensive experience in phosphate surveys while working for a sugar beet company (Lambert 1998). He was acclaimed as one of the first people to suggest phosphate surveys could be used to prospect for archaeological sites. Since then, phosphate surveys have fluctuated in their use within archaeology, but have continued to be essential for farmers to maintain soil nutrient levels.

Companies and farmers using precision farming methods take a detailed interest in soil geochemistry. It is important for them to monitor and adjust macronutrient (N, P, K, Mg) and micronutrient levels every few years according to what the crop is expected to need and the nutrients expected to leave the field with the crop (Heege 2013). Macronutrients are routinely tested every three to 4 years in the UK at a field level,

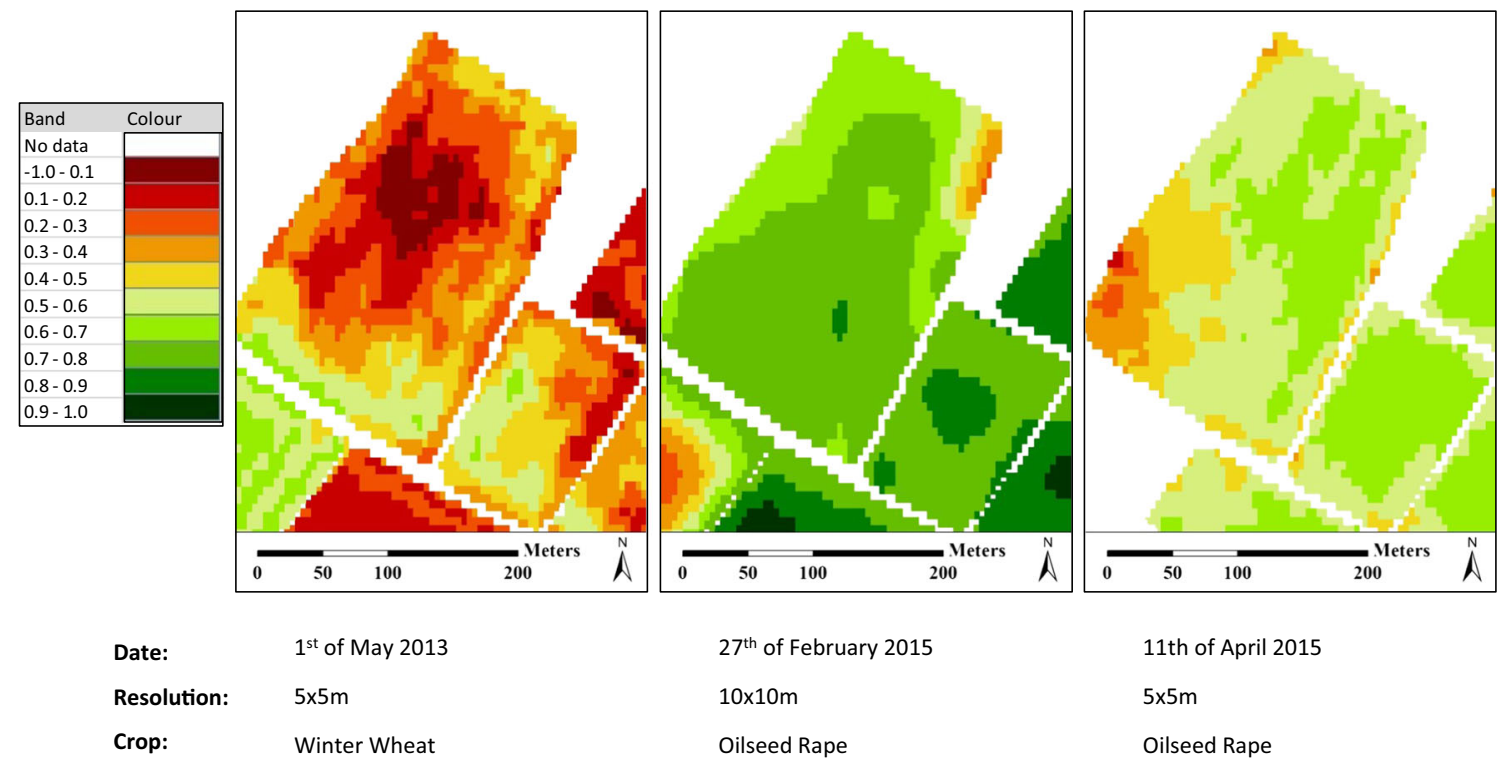

Fig. 3 NDVI images of the same field under different crops and at different resolutions 
but today with precision farming, most soil sampling is targeted to specific soil zones, or a systematic hectare grid, providing more detailed spatial information about nutrient variations than before.

Since Arrhenius' work, it has been recognised that archaeological sites do not only exhibit variations in phosphate. Archaeological sites have the potential to enhance or deplete levels of many stable nutrients due to the sites' history. Research has shown that elements such as $\mathrm{Ba}, \mathrm{Ca}, \mathrm{Cu}, \mathrm{P}, \mathrm{Pb}$, $\mathrm{Zn}$ and $\mathrm{Sr}$ are often found in conjunction with archaeological activities (Wilson et al. 2008). Little research has, however, been directed at the implications of these geochemical variations from an agronomic point of view. As precision farming represents attention to detail in soils and crops, it seems there needs to be better understanding of how archaeological sites contribute to agronomic variation.

Figure 5 gives some visual representation of one example demonstrating this geochemical interconnection. There is an enhancement of zinc surrounding the area interpreted from the geophysical survey and confirmed with excavation, to be a Neolithic henge. This enhancement is twice the average values of the surrounding soils. The question is, is this enhancement due to the complexity of soil variations in this field? Or is it caused by the human activity involved in creation of the henge, or is it evidence of other activities on the site?

There are several plausible reasons for this enhancement. The zinc values in the topsoil surrounding the henge are not the highest in the field, with the southern part of the field being consistently above $40 \mathrm{ppm}$. The soil type here has developed on top of a chalk bedrock, with the rest of the field assumed to be on a greensand geology. This assumption, from existing soil maps, however has been found to not be a true representation of the soil variability within the field. Instead, there is a much more complex situation with a band of greensand curving around the visible archaeological features in the geophysical survey. The archaeological features themselves sit on top of a chalk promontory that fluctuates in depth with a mixed horizon boundary.

Therefore, it is possible that the elevated zinc concentration is coming from these chalk-based topsoils, but the digging of the henge has increased the amount of mixing of soil horizons, creating the affect that the henge shows more strongly than other areas on similar chalk-based topsoils. Adding in further complexity is a number of pits that surround the henge identified in aerial photographs and the geophysical survey and the possibility of other sources of zinc inputs into the soil (such as through manures and other activities). Due to only topsoil samples being studied in this instance, the mixing of the soil horizons could mean several different sources for this variation in zinc and until further research evaluates this in more detail, no firm conclusions can be made.

Yet, this example demonstrates the complex situation that archaeological sites present in relation to their effect on soil geochemistry and their relationship with complex soil variations; it also shows the potential benefits of high-resolution data that archaeologists have collected for our understanding of soil variations on an agriculturally relevant scale.

\section{Concluding remarks}

The growth and future of the global agricultural industry will almost certainly rely on better use of technology and better understanding of what farmers do, how they do it and what impacts that has. As part of this, knowledge of the soils that underpin crop growth and the archaeological remains that add to the variability of soils is crucial. From examples presented here, there seem to be many common interests between the archaeological and agricultural communities in the UK, with great potential for building archaeological evidence into modern agricultural management regimes. It must also be recognised that this is not limited to just the UK; agricultural technology is becoming far more prevalent from South America to Asia, and the underlying connections between archaeological sites, soils and agricultural management will still exist, be it within different archaeological and agricultural systems.

However, there are also some significant areas that warrant further discussion and research. Not only is there a need to understand the causes of variability on such case study sites, whether archaeological or not, but also on practical aspects of accessing and using this data responsibly. Primarily, these ideas rely on the basis of access to data from farmers and agricultural companies. Depending on who and how this data gets used, this sort of access may prove complicated in situations where the locations of vulnerable archaeological sites may need to be restricted, or where a farmer's data might be confidential. On an individual case by case basis, archaeologists aware of these datasets could simply ask farmers whether they have any potentially useful data for example. But if considering this as a large-scale approach to join datasets up, dealings between agricultural companies and archaeological bodies/companies may require different approaches with clearly set out objectives and formal agreements.

This having been said, it may be that in some cases, farmers may not want to understand more about the archaeology in their soil for fear of interference in their farming operations for example. While certainly possible, it is also possible that where important sites have been designated to protect them, there is little actual evidence for their extents, meaning over restricting areas with no archaeological significance. In which case, it may be possible to work more collaboratively to improve the farmers' ability to grow crops and to help inform better archaeological decision-making.

For these questions to be answered, it is necessary that more future research is targeted at building better case studies 
Fig. 5 Caesium magnetometer survey and interpretation courtesy of Historic England (Linford et al. 2015) (left) and the variation in zinc within the topsoil at the same site (right)

\section{Case study site in Wiltshire, UK NGR SU092573}

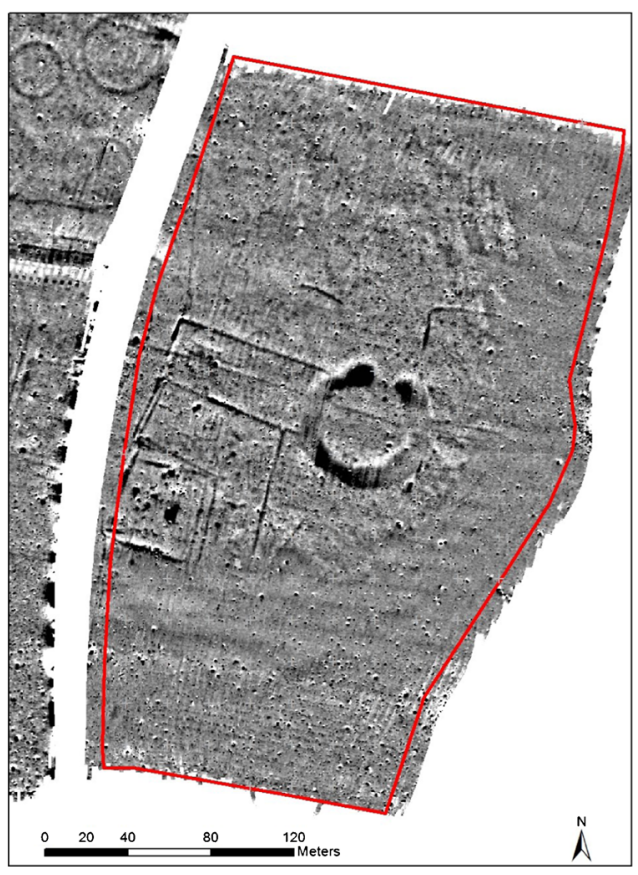

and an evidence base with which these ideas can be tested. It is hoped that this paper has described some of the potential between archaeology and precision farming and promoted the discussion of these ideas across many archaeological communities.

Acknowledgements This research is being conducted as part of an Arts and Humanities Research Council (South West and Wales Doctoral Training Partnership) PhD studentship. We wish to thank the many people who have contributed time and advice to this research from the farming community, the precision farming industry and Historic England.

Open Access This article is distributed under the terms of the Creative Commons Attribution 4.0 International License (http:// creativecommons.org/licenses/by/4.0/), which permits unrestricted use, distribution, and reproduction in any medium, provided you give appropriate credit to the original author(s) and the source, provide a link to the Creative Commons license, and indicate if changes were made.

\section{References}

Allred B, Daniels J, Mohammed RE (2008) Handbook of agricultural geophysics. CRC Press, Florida

Green, A., 2014 A multi-disciplinary investigation of large oval enclosures within Wessex. Dissertation (MSc in Applied Sciences by Research). Bournemouth University. Unpublished

Heege JH (2013) Precision in crop farming: site specific concepts and sensing methods: applications and results. Springer, Dordrecht

Joint Research Centre (JRC) of the European Commission and the Monitoring Agriculture Resources (MARS) Unit H04 2014 Precision agriculture: an opportunity for EU farmers-potential support with the CAP 2014-2020, Policy Department B: Structural and Cohesion Policies, Agricultural and Rural Development, European Parliament.

Lamb DW, Brown RB (2001) Review paper: remote-sensing and mapping of weeds in crops. J. Agric. Eng Res 78(2):117-125 doi: 10.1006

Lambert JB (1998) Traces of the past: unraveling the secrets of archaeology through chemistry. Perseus Publishing, USA

Linford N, Linford P, Payne A (2015) Chasing aeroplanes: developing a vehicle-towed caesium magnetometer array to complement aerial photography over three recently surveyed sites in the UK. Near Surf Geophys 13(6):623-631

McBratney A, Whelan B, Thomir A, Bouma J (2005) Future directions of precision agriculture. Precis Agric 6:7-23

Mulla DJ (2013) Special issue: sensing in agriculture review twenty five years of remote sensing in precision agriculture: key advances and remaining knowledge gaps. Biosyst Eng 114:358-371. https://doi. org/10.1016/j.biosystemseng.2012.08.009.

Oliver MA, Bishop T, Marchant B (2013) Precision agriculture for sustainability and environmental protection. Routledge, Oxon

Parliamentary Office for Science and Technology 2015 Precision farming-POSTnote 505, http://researchbriefings.parliament.uk/ ResearchBriefing/Summary/POST-PN-0505 accessed on 7 November 2016

Seelan SK, Laguette S, Casady GM, Seielstad GA (2003) Remote sensing applications for precision agriculture: a learning community approach. Remote Sens Environ 88(1-2):157-169. https://doi.org/10. 1016/j.rse.2003.04.007

Stafford JV (2000) Implementing precision agriculture in the 21st century. J Agric Eng Res 76(3):267-275

Whelan B and McBratney A 2003 Definition and interpretation of potential management zones in Australia, Proceedings of the 11th Australian Agronomy Conference, pp. 2-6. Available at: www. usyd.edu.au/su/agric/acpa (Accessed: 14 November 2016) 
Wilson CA, Davidson DA, Cresser MS (2008) Multi-element soil analysis: an assessment of its potential as an aid to archaeological interpretation. J Archaeol Sci 35(2):412-424. https://doi.org/10.1016/j. jas.2007.04.006

Zhang N, Wang M, Wang N (2002) Precision agriculture - a worldwide overview. Comput Electron Agric 36(2):113-132 http://www.ipf-uk.com/precision-farming/soil-zoning/soil-brightness. html accessed 27 February 2016

http://www.nesta.org.uk/blog/precision-agriculture-separating-wheatchaff accessed on 7 November 2016

https://sa.catapult.org.uk/documents/10625/53165/The+Courtyard+ Partnership+case+study/26073572-f15f-41ae-8480-9857b682e84e accessed 27 February 2016 